\title{
Predicting the minimum clinically important difference in patients undergoing surgery for the treatment of degenerative cervical myelopathy
}

\author{
Lindsay Tetreault, PhD, ${ }^{1}$ Jefferson R. Wilson, MD, PhD, ${ }^{1}$ Mark R. N. Kotter, MD, PhD, ${ }^{1}$ \\ Aria Nouri, MD, MSc, ${ }^{1}$ Pierre Côté, PhD, ${ }^{2}$ Branko Kopjar, MD, PhD, ${ }^{3}$ Paul M. Arnold, MD, ${ }^{4}$ and \\ Michael G. Fehlings, MD, PhD'
}

1Division of Neurosurgery, Toronto Western Hospital, University Health Network, Toronto; ${ }^{2}$ University of Ontario Institute of Technology, Faculty of Health Sciences, Oshawa, Ontario, Canada; ' ${ }^{3}$ Department of Health Services, School of Public Health, University of Washington, Seattle, Washington; and ${ }^{4}$ Department of Neurosurgery, University of Kansas, Kansas City, Kansas

\begin{abstract}
OBJECTIVE The minimum clinically important difference (MCID) is defined as the minimum change in a measurement that a patient would identify as beneficial. Before undergoing surgery, patients are likely to inquire about the ultimate goals of the operation and of their chances of experiencing meaningful improvements. The objective of this study was to define significant predictors of achieving an MCID on the modified Japanese Orthopaedic Association (mJOA) scale at 2 years following surgery for the treatment of degenerative cervical myelopathy (DCM).
\end{abstract}

METHODS Seven hundred fifty-seven patients were prospectively enrolled in either the AOSpine North America or International study at 26 global sites. Fourteen patients had a perfect preoperative mJOA score of 18 and were excluded from this analysis $(n=743)$. Data were collected for each participating subject, including demographic information, symptomatology, medical history, causative pathology, and functional impairment. Univariate log-binominal regression analyses were conducted to evaluate the association between preoperative clinical factors and achieving an MCID on the mJOA scale. Modified Poisson regression using robust error variances was used to create the final multivariate model and compute the relative risk for each predictor.

RESULTS The sample consisted of 463 men (62.31\%) and 280 women (37.69\%), with an average age of $56.48 \pm 11.85$ years. At 2 years following surgery, patients exhibited a mean change in functional status of $2.71 \pm 2.89$ points on the mJOA scale. Of the 687 patients with available follow-up data, $481(70.01 \%)$ exhibited meaningful gains on the mJOA scale, whereas $206(29.98 \%)$ failed to achieve an MCID. Based on univariate analysis, significant predictors of achieving the MCID on the mJOA scale were younger age; female sex; shorter duration of symptoms; nonsmoking status; a lower comorbidity score and absence of cardiovascular disease; and absence of upgoing plantar responses, lower-limb spasticity, and broad-based unstable gait. The final model included age (relative risk [RR] 0.924, $p<0.0001$ ), smoking status ( $R R 0.837, p=0.0043$ ), broad-based unstable gait ( $R R 0.869, p=0.0036)$, and duration of symptoms ( $R R 0.943$, $\mathrm{p}=0.0003)$.

CONCLUSIONS In this large multinational prospective cohort, $70 \%$ of patients treated surgically for DCM exhibited a meaningful functional gain on the mJOA scale. The key predictors of achieving an MCID on the mJOA scale were younger age, shorter duration of symptoms, nonsmoking status, and lack of significant gait impairment.

http://thejns.org/doi/abs/10.3171/2016.3.FOCUS1665

KEY WORDS degenerative cervical myelopathy; cervical spondylotic myelopathy; minimum clinically important difference; MCID; outcome prediction; surgical outcomes

$\mathrm{D}$ EGENERATIVE cervical myelopathy (DCM) is a progressive degenerative spine condition and is the most common cause of spinal cord dysfunction in adults worldwide. ${ }^{7}$ DCM is an umbrella term that encompasses all forms of degenerative changes to the cervi- cal spine, including spondylosis, hypertrophy or ossification of the spinal ligaments, disc herniation, and subluxation. ${ }^{17,26}$ DCM results in progressive compression of the spinal cord and can manifest as an array of neurological signs and symptoms, such as hyperreflexia, atrophy of in-

ABBREVIATIONS DCM = degenerative cervical myelopathy; $M C I D=$ minimum clinically important difference; $\mathrm{mJOA}=$ modified Japanese Orthopaedic Association . SUBMITTED February 1, 2016. ACCEPTED March 16, 2016. INCLUDE WHEN CITING DOI: 10.3171/2016.3.FOCUS1665. 
trinsic hand muscles, and gait dysfunction..$^{29}$ Patients with DCM may have substantial functional impairment, significantly reduced quality of life, and be unable to perform certain activities of daily living.

Surgery is typically recommended as the preferred management strategy for patients with clinical and imaging evidence of DCM. ${ }^{5,8}$ In general, surgical decompression of the cervical spine is effective at halting neurological deterioration, relieving certain symptoms, and improving functional status and quality of life. The minimum clinically important difference (MCID) is defined as the minimum change in a measurement that a patient would identify as beneficial. ${ }^{3,19,20}$ Based on two recent prospective studies, patients, on average, exhibited a 2.40- to 2.88-point gain on the modified Japanese Orthopaedic Association (mJOA) scale following surgery, an improvement exceeding the overall MCID for this metric (2 points). ${ }^{2,5,8,28}$

The MCID of the mJOA scale, however, varies based on preoperative myelopathy severity: 1 point for mild myelopathy (mJOA $\geq 15), 2$ points for moderate myelopathy (mJOA score of 12-14), and 3 points for severe disease (mJOA score < 12). ${ }^{28}$ Before undergoing surgery, patients are likely to inquire about the ultimate goals of the operation and of their chances of experiencing meaningful improvements in functional status. Although several highquality prognostic studies exist in the literature, no study has examined important predictors of achieving an MCID on the mJOA scale. This knowledge is critically important to patients and is essential to appropriately manage their expectations regarding the outcomes of surgery, increase satisfaction, and provide decision-making support to surgeons.

The objective of this study was to define significant predictors of achieving an MCID on the mJOA scale at 2 years following surgery for the treatment of DCM.

\section{Methods \\ Patients}

Seven hundred fifty-seven patients were prospectively enrolled in either the AOSpine North America $(\mathrm{n}=278)$ or International $(n=479)$ study at 26 global sites. Centers were asked to participate if they were either high-volume private practices or academic institutions and if they had experience conducting prospective clinical research. Investigators were neurosurgeons or orthopedic spine surgeons. Ethical approval was obtained from each site's institutional review board.

The inclusion criteria for both studies were identical: 1) age 18 years or older; 2) symptomatic DCM with at least one clinical sign of myelopathy; 3) imaging evidence of cervical cord compression; and 4) no previous cervical spine surgery. Patients were excluded if they were asymptomatic or had a diagnosis of active infection, neoplastic disease, rheumatoid arthritis, ankylosing spondylitis, or concomitant symptomatic lumbar stenosis. Verbal and written informed consent was obtained from each participant.

\section{Surgical Intervention}

All patients underwent surgical decompression of the cervical spine. The attending surgeon decided what ap- proach to use, the number of levels to operate on, and whether to use fusion or instrumentation. Patients were either treated anteriorly, posteriorly, or with a 2-stage anterior-posterior surgery. Anterior techniques included discectomy and/or corpectomy with fusion. Patients operated on posteriorly underwent either laminectomy with or without fusion or laminoplasty.

\section{Data Collection}

Extensive data were collected for each participant, including demographic information, symptomatology, medical history, causative pathology and surgical summary. Each patient was clinically examined at baseline and at 6-, $12-$, and 24-month intervals following surgery. Functional impairment was measured using the mJOA and Nurick scales, disability was evaluated using the Neck Disability Index, and quality of life was assessed using the SF-36 version 2 .

The primary outcome measure for this study was the mJOA score. The mJOA scale is an investigator-administered DCM-specific index that separately addresses motor function of the upper and lower extremities, sensory function of the upper extremities, and sphincter function. A score of 18 indicates normal function, whereas a lower score reflects more severe neurological impairment. Kopjar et al., ${ }^{13}$ in 2015, evaluated the psychometric properties of this scale and reported that it is composed of two dimensions, has moderate internal consistency, is responsive to change, and demonstrates both convergent and divergent validity. The reliability of the mJOA scale has not been established; however, the inter- and intrarater reliabilities of the JOA scale are high.

\section{External Monitoring}

External research monitors performed onsite evaluations to ensure that the data were accurate, reliable, and complete and that the study was conducted in compliance with the protocol. All data were transcribed into an electronic data capture system and were processed at the AOSpine clinical research network data management center.

\section{Statistical Analysis}

Continuous variables were described using means, standard deviations, and ranges. Categorical variables were summarized using frequencies and percentages.

A last-observation-carry-forward approach was used to impute missing data at 24 months. Change in mJOA score was calculated by subtracting a patient's preoperative score from his/her 24-month follow-up score. An "optimal" outcome was defined as a change in mJOA score greater than or equal to the MCID of this scale. For patients with severe myelopathy (mJOA score $<12$ ), the MCID is 3 points; for those with moderate disease (mJOA score of 12-14), the MCID is 2 points; and for those with mild disease (mJOA score $\geq 15$ ), the MCID is 1 point. A "suboptimal" outcome was classified as a change in mJOA score that was less than the MCID, no change in status, or functional deterioration.

Univariate log-binomial regression analyses were conducted to evaluate the association between several pre- 
operative factors and surgical outcomes. Variables that yielded a $p$ value $<0.20$ in univariate analysis were further examined in a multivariate analysis. Variables that were considered clinically relevant but had a $p$ value $>0.2$ were also assessed in multivariate analyses. Multicollinearity was evaluated by calculating tolerance. Modified Poisson regression using robust error variances was used to create the final multivariate model and compute the relative risk for each predictor.

\section{Results \\ Patients}

Four hundred one participants (52.97\%) were enrolled at sites in North America (278 from North American study, 123 from International study), 150 (19.82\%) in Asia Pacific, 126 (16.64\%) in Europe, and 80 (10.57\%) in Latin America. Of these 757 participants, 14 were excluded from this analysis because they scored the maximum preoperative mJOA score of 18 . Table 1 summarizes enrollment by site.

Our cohort consisted of $463(62.31 \%)$ men and 280 (37.69\%) women, with an average age of $56.48 \pm 11.85$ years (range $21-87$ years). Patients presented with a wide array of neurological signs and symptoms, including hyperreflexia $(77.90 \%)$, corticospinal distribution motor deficits $(62.80 \%)$, numb hands $(89.49 \%)$, weakness $(82.88 \%)$, and gait impairment (76.55\%). The average baseline mJOA score was $12.52 \pm 2.74$ (range 3-17 points), with 193 presenting with mild myelopathy (mJOA score of 15-17), 296 with moderate disease (mJOA score of 12-14), and 254 with severe disease (mJOA score < 12). Four hundred fifty-nine patients $(61.78 \%)$ suffered from comorbidities, with the most common being cardiovascular (44.95\%), endocrine (18.17\%), and gastrointestinal (16.15\%) disorders. With respect to causative pathology, $77.25 \%$ of patients displayed evidence of spondylosis, $71.74 \%$ of disc herniation, and $24.23 \%$ of a hypertrophied ligamentum flavum. A smaller percentage of patients presented with ossification of the posterior longitudinal ligament $(21.13 \%)$ and subluxation $(5.79 \%)$.

All 743 patients underwent surgical decompression of their cervical spine: $436(58.68 \%)$ were treated anteriorly, 284 (38.22\%) posteriorly, and 23 (3.10\%) underwent a 2-stage anterior-posterior surgery. The mean number of decompressed segments was $3.74 \pm 1.27$ (range 1-7 levels), and the mean operative duration was $180.70 \pm 80.03 \mathrm{~min}-$ utes (range 45-575 minutes). Table 2 displays a complete summary of the demographics and surgical characteristics of patients enrolled in the International and North American studies.

\section{4-Month Follow-Up}

Five hundred fifty $(74.02 \%)$ of the 743 patients attended their 2-year follow-up visit and were evaluated for improvements in functional status (mean mJOA score $15.34 \pm 2.64$, range 7-18). Following imputation, mJOA data were available for 687 participants $(92.46 \%$ ) (mean mJOA score $15.26 \pm 2.77$, range $2-18$ ). The mean change in functional status was $2.71 \pm 2.89$ points (range -10 to 14) on the mJOA scale. One hundred twenty-four patients (68.89\%) with mild myelopathy, 201 (72.04\%) with mod-
TABLE 1. Participating centers and respective enrolled patients

\begin{tabular}{lc}
\hline \multicolumn{1}{c}{ Site } & No. of Enrolled Patients (\%) \\
\hline Medical University of Ancona & $9(1.21)$ \\
\hline Emory University & $50(6.73)$ \\
\hline Johns Hopkins University & $4(0.54)$ \\
\hline New England Baptist Hospital & $13(1.75)$ \\
\hline Brigham and Women's Hospital & $2(0.27)$ \\
\hline Canisius Wilhelmina Hospital & $41(5.52)$ \\
\hline Hospital San Juan de Dios & $4(0.54)$ \\
\hline Medical University of Catania & $40(5.38)$ \\
\hline Southwestern Hospital & $39(5.25)$ \\
\hline University of Virginia & $17(2.29)$ \\
\hline Beaumont Hospital & $4(0.54)$ \\
\hline Indiana Spine Group & $5(0.67)$ \\
\hline Ege University & $29(3.90)$ \\
\hline Kansas University Medical Center & $79(10.63)$ \\
\hline Chubu Rosai Hospital & $19(2.56)$ \\
\hline All India Institute of Medicine & $57(7.67)$ \\
\hline Okayama University & $7(0.94)$ \\
\hline University of São Paulo & $56(7.54)$ \\
\hline Thomas Jefferson University & $29(3.90)$ \\
\hline Mayo Clinic & $1(0.13)$ \\
\hline Tan Tock Seng Hospital & $19(2.56)$ \\
\hline University of Utah & $18(2.42)$ \\
\hline Hospital Santa Marcelina & $17(2.29)$ \\
\hline Teikyo University Chiba Medical Center & $7(0.94)$ \\
\hline Spine Education and Research Institute & $4(0.54)$ \\
\hline Toronto Western Hospital & $173(23.28)$ \\
\hline &
\end{tabular}

erate myelopathy and $156(68.42 \%)$ with severe disease exhibited clinically meaningful changes in functional status and achieved the MCID of the mJOA score (mild $\geq$ 1 point, moderate $\geq 2$ points, and severe $\geq 3$ points). In total, $481(70.01 \%)$ of the 687 patients had an "optimal" surgical outcome, whereas 206 (29.98\%) failed to improve by greater than or equal to the MCID. Of these 206 patients, 75 (or $10.92 \%$ of the 687 participants) exhibited an improvement less than the MCID, 54 (7.86\%) stayed the same, and $77(11.21 \%)$ deteriorated.

\section{Univariate Analysis}

Based on univariate analysis, the significant predictors of achieving the MCID on the mJOA scale were younger age (relative risk [RR] 0.918, $\mathrm{p}<0.0001$ ); female sex (RR $0.881, \mathrm{p}=0.010)$; shorter duration of symptoms (RR 0.938, $\mathrm{p}=0.0001)$; nonsmoking status ( $R R \quad 0.869, \mathrm{p}=0.025)$; a lower morbidity score (RR 0.966, $\mathrm{p}=0.035)$ and absence of comorbidities; and absence of upgoing plantar responses (RR 0.885, $\mathrm{p}=0.028)$, lower-limb spasticity (RR 0.856 , $\mathrm{p}=0.0025)$, and broad-based unstable gait (RR 0.847, $\mathrm{p}$ $=0.0007)$. The associations between this outcome and gastrointestinal disorders, endocrine comorbidities, and hyperreflexia yielded $\mathrm{p}$ values $<0.20$ and these variables were evaluated in multivariate analysis (Table 3). 
TABLE 2. Patient baseline demographic information on 743 patients with degenerative cervical myelopathy enrolled in either the AOSpine North America or International study*

\begin{tabular}{|c|c|}
\hline Variable & Total Sample \\
\hline Baseline severity score (mJOA) & $12.52 \pm 2.74(3-17)$ \\
\hline Mild (mJOA $\geq 15)$ & $193(25.98 \%)$ \\
\hline Moderate $(\mathrm{mJOA}=12-14)$ & $296(39.84 \%)$ \\
\hline Severe (mJOA <12) & $254(34.19 \%)$ \\
\hline Age (yrs) & $56.48 \pm 11.85(21-87)$ \\
\hline Gender (\%) & $463(62.31 \%) M$ \\
\hline Duration of symptoms, mos $(n=743)$ & $26.79 \pm 39.25(0.25-432)$ \\
\hline$<3 \mathrm{mos}$ & $118(15.88 \%)$ \\
\hline$\geq 3 \mathrm{mos},<6 \mathrm{mos}$ & $113(15.21 \%)$ \\
\hline$\geq 6 \mathrm{mos},<12 \mathrm{mos}$ & $162(21.80 \%)$ \\
\hline$\geq 12 \mathrm{mos},<24 \mathrm{mos}$ & $152(20.46 \%)$ \\
\hline$\geq 24 \mathrm{mos}$ & $198(26.65 \%)$ \\
\hline Smoking status $(\%)$ & $199(26.78 \%)$ \\
\hline Comorbidities (\%) & $459(61.78 \%)$ \\
\hline Comorbidity score & $1.45 \pm 1.82(0-13)$ \\
\hline Cardiovascular & $334(44.95 \%)$ \\
\hline Respiratory & $80(10.77 \%)$ \\
\hline Gastrointestinal & $120(16.15 \%)$ \\
\hline Renal & $22(2.96 \%)$ \\
\hline Endocrine & $135(18.17 \%)$ \\
\hline Psychiatric & $103(13.86 \%)$ \\
\hline Rheumatological & $38(5.11 \%)$ \\
\hline Neurological & $47(6.33 \%)$ \\
\hline \multicolumn{2}{|l|}{ Diagnosis } \\
\hline Spondylosis & $574(77.25 \%)$ \\
\hline Disc herniation & $533(71.74 \%)$ \\
\hline OPLL & $157(21.13 \%)$ \\
\hline HLF & $180(24.23 \%)$ \\
\hline Subluxation & $43(5.79 \%)$ \\
\hline \multicolumn{2}{|l|}{ Symptoms $(n=742)$} \\
\hline Numb hands & $664(89.49 \%)$ \\
\hline Clumsy hands & $556(74.93 \%)$ \\
\hline Impaired gait & $568(76.55 \%)$ \\
\hline Bilateral arm paresthesia & $422(56.87 \%)$ \\
\hline L'Hermitte's phenomena & $198(26.68 \%)$ \\
\hline General weakness & $615(82.88 \%)$ \\
\hline \multicolumn{2}{|l|}{ Signs $(n=742)$} \\
\hline Corticospinal motor deficits & $466(62.80 \%)$ \\
\hline Atrophy of intrinsic hand muscles & $268(36.12 \%)$ \\
\hline Hyperreflexia & $578(77.90 \%)$ \\
\hline Positive Hoffman's sign & $465(62.67 \%)$ \\
\hline Upgoing plantar responses & $266(35.85 \%)$ \\
\hline Lower-limb spasticity & $353(47.57 \%)$ \\
\hline Broad-based unstable gait & $442(59.57 \%)$ \\
\hline
\end{tabular}

$\mathrm{HLF}=$ hypertrophy of the ligamentum flavum; OPLL = ossification of the posterior longitudinal ligament.

* Continuous variables are described using means \pm standard deviations and ranges. Baseline categorical variables are summarized as percentages.

\section{Multivariate Analysis}

The final model consisted of 4 statistically significant and clinically relevant predictors: age (RR [by decade] $0.924,95 \%$ CI $0.889-0.960, \mathrm{p}<0.0001)$, smoking sta-
TABLE 3. Univariate analyses evaluating the association between various clinical predictors and achieving an MCID on the MJOA scale at 2 years following surgery

\begin{tabular}{lccc}
\hline \multicolumn{1}{c}{ Predictor } & $\begin{array}{c}\text { Relative } \\
\text { Risk }\end{array}$ & 95\% Cl & p Value \\
\hline Baseline severity score (mJOA) & 0.991 & $0.973-1.009$ & 0.335 \\
\hline Age (by decade) & 0.918 & $0.881-0.955$ & $<0.0001$ \\
\hline Gender (ref = female) & 0.881 & $0.800-0.970$ & 0.010 \\
\hline Duration of symptoms & 0.938 & $0.907-0.969$ & 0.0001 \\
\hline Smoking status (ref = no) & 0.869 & $0.768-0.982$ & 0.025 \\
\hline Comorbidities (ref = absence) & 0.948 & $0.859-1.046$ & 0.285 \\
Comorbidity score* & 0.966 & $0.935-0.998$ & 0.035 \\
Cardiovascular & 0.894 & $0.808-0.989$ & 0.029 \\
Respiratory & 0.918 & $0.767-1.097$ & 0.345 \\
Gastrointestinal & 1.118 & $0.996-1.255$ & 0.060 \\
Renal & 1.095 & $0.837-1.432$ & 0.508 \\
Endocrine & 0.879 & $0.760-1.016$ & 0.080 \\
Psychiatric & 1.058 & $0.929-1.206$ & 0.397 \\
Rheumatological & 0.867 & $0.665-1.130$ & 0.291 \\
Neurological & 0.972 & $0.790-1.197$ & 0.790 \\
\hline Symptoms (ref = absence) & & & \\
Numb hands & 1.073 & $0.899-1.280$ & 0.435 \\
Clumsy hands & 0.997 & $0.890-1.116$ & 0.958 \\
Impaired gait & 0.913 & $0.821-1.014$ & 0.090 \\
Bilateral arm paresthesia & 1.032 & $0.934-1.141$ & 0.531 \\
L'Hermitte's phenomena & 0.985 & $0.880-1.102$ & 0.790 \\
General weakness & 0.952 & $0.842-1.077$ & 0.438 \\
\hline Signs (ref = absence) & & & \\
Corticospinal motor deficits & 0.955 & $0.865-1.055$ & 0.367 \\
Atrophy of intrinsic hand & 0.992 & $0.896-1.100$ & 0.885 \\
$\quad$ muscles & & & \\
Hyperreflexia & 0.917 & $0.823-1.023$ & 0.120 \\
Positive Hoffman's sign & 1.010 & $0.912-1.119$ & 0.845 \\
Upgoing plantar responses & 0.885 & $0.794-0.987$ & 0.028 \\
Lower-limb spasticity & 0.856 & $0.774-0.947$ & 0.0025 \\
Broad-based unstable gait & 0.847 & $0.770-0.932$ & 0.0007 \\
\hline Ref = reference. & & & \\
* Comorbidity score comprises both number and & severity of comorbidities.
\end{tabular}

tus (RR [ref $=$ nonsmoker] $0.837,95 \%$ CI $0.741-0.946, \mathrm{p}$ $=0.0043)$, broad-based unstable gait $(\mathrm{RR}$ [ref $=$ absent] $0.869,95 \%$ CI $0.791-0.955, \mathrm{p}=0.0036$ ), and duration of symptoms (RR 0.943, 95\% CI 0.913-0.974, $\mathrm{p}=0.0003$ ).

Based on relative risks, the probability of achieving a score greater than or equal to the MCID on the mJOA scale 1) decreases by approximately $6 \%$ when a patient has an increased duration of symptoms (i.e., moves from the $\leq 3$-month to the 3 to 6 -month group); 2) decreases by approximately $8 \%$ for every decade increase in age; 3 ) decreases by $13 \%$ when a patient presents with gait impairment (vs no impairment); and 4) decreases by $16 \%$ when a patient smokes (Table 4). To better interpret the impact of age on outcomes, Table 5 presents, by decade, the percentage of patients who achieved the MCID on the mJOA scale versus those who experienced a decline in function. 
TABLE 4. Multivariate analyses evaluating the association between various clinical predictors and achieving an MCID on the mJOA scale at 2 years following surgery

\begin{tabular}{lcrr}
\hline \multicolumn{1}{c}{ Predictor } & $\begin{array}{c}\text { Relative } \\
\text { Risk }\end{array}$ & $95 \% \mathrm{Cl}$ & $\mathrm{p}$ Value \\
\hline Smoking status (ref = nonsmoker) & 0.837 & $0.741-0.946$ & 0.0043 \\
\hline Age (by decade) & 0.924 & $0.889-0.960$ & $<0.0001$ \\
\hline $\begin{array}{l}\text { Broad-based unstable gait (ref }= \\
\text { absence) }\end{array}$ & 0.869 & $0.791-0.955$ & 0.0036 \\
\hline Duration of symptoms & 0.943 & $0.913-0.974$ & 0.0003 \\
\hline
\end{tabular}

\section{Discussion}

This study aimed to identify important predictors of achieving an MCID in functional status following surgery for the treatment of DCM. Based on our results, we found that patients are more likely to exhibit a clinically important improvement if they are younger, do not smoke, have a shorter duration of symptoms, and do not present with a broad-based unstable gait. These factors have previously been identified as important predictors of outcomes, but this is the first study to use a severity-dependent MCID as the dependent variable.

The objectives of surgery are, first, to halt the progression of myelopathy and, second, to improve neurological impairment, functional disability, and quality of life. ${ }^{8}$ In our study, 610 patients $(88.79 \%)$ either stayed the same or improved, while 77 patients (11.21\%) deteriorated based on mJOA scale scores. The MCID is a metric that describes a change in status that a patient would define as meaningful. For the mJOA scale, the MCID varies based on severity: patients with more severe myelopathy must make larger gains than those with mild disease to consider their improvement as important. Our model can be used to predict which patients are likely to achieve meaningful improvements in impairment. This information is valuable to the patient and should be used to discuss the probable outcome of the surgery and to appropriately manage expectations. These expectations are closely linked to patient satisfaction, which is of increasing importance in performance-based health care systems..$^{27}$

Older patients are less likely to attain an "optimal" outcome on the mJOA scale. Older patients, however, are more severely impaired and therefore require a larger improvement to achieve an MCID. In a study by Nakashima et al., age was identified as an independent predictor of improvement on the mJOA scale, after controlling for baseline severity score, comorbidities, and surgical factors. ${ }^{16}$ Elderly patients may not be able to translate neurological improvements to functional recovery as well as younger patients; however, despite this, the elderly do achieve similar improvements in disability and quality of life as evaluated by the Neck Disability Index and SF-36 Physical and Mental Component scores. Along with more severe degenerative changes, the elderly may experience age-related alterations to the composition of their spinal cord. ${ }^{6}$ Advancing age is significantly correlated with a decreased density of small myelinated fibers in the cortico-
TABLE 5. Impact of age on achieving an MCID on the mJOA scale 2 years after surgery*

\begin{tabular}{lcc}
\hline & \multicolumn{2}{c}{ No. of Patients (\%) } \\
\cline { 2 - 3 } Age Decade $(y r s)$ & $\begin{array}{c}\text { Achieved the MCID } \\
\text { on the mJOA Scale }\end{array}$ & $\begin{array}{c}\text { Experienced Decline } \\
\text { in the mJOA Score }\end{array}$ \\
\hline $20-29(n=7)$ & $7(100.00)$ & $0(0.00)$ \\
\hline $30-39(n=45)$ & $39(86.67)$ & $2(4.44)$ \\
\hline $40-49(n=137)$ & $97(70.80)$ & $17(12.41)$ \\
\hline $50-59(n=222)$ & $162(72.97)$ & $24(10.81)$ \\
\hline $60-69(n=176)$ & $122(69.32)$ & $18(10.23)$ \\
\hline $70-79(n=84)$ & $46(54.76)$ & $16(19.05)$ \\
\hline $80-89(n=16)$ & $8(50.00)$ & $0(0.00)$ \\
\hline * mJOA data were available for 687 patients after imputation. A decline in \\
status was defined as a negative change in mJOA score between baseline and \\
2 years postoperatively.
\end{tabular}

spinal tract and a reduced number of alpha and gamma motor neurons and small neurons in the intermediate zone of the ventral horn. ${ }^{24,25}$ Other potential explanations for the association between age and outcome include the following: 1) mJOA scoring may be affected by other aspects of the natural aging process, including hip and knee osteoarthritis, sarcopenia, and lumbar canal stenosis; and 2) the elderly have reduced physiological reserves and may be less tolerant of surgery. ${ }^{16}$ Throughout the literature, although less effective, surgery still halts disease progression in elderly patients and, in some cases, results in significant improvements in functional status and quality of life. Surgeons should therefore not discriminate on the basis of age but use this information to appropriately manage their patients' expectations. Future studies are required to determine if there is a cut-off age above which the risks of surgery outweigh the benefits.

Patients who smoke are also less likely to achieve an MCID on the mJOA scale. In preclinical studies, tobacco smoking has been associated with increased intervertebral disc degeneration, decreased bone mineral density and reduced microstructural integrity of cerebral white matter. ${ }^{9,11,31}$ Furthermore, nicotine treatment results in stenosis of and a decrease in the number of vascular bulbs, enlargement of vascular endothelial cells, and reduced blood flow. ${ }^{11}$ Smoking may therefore amplify the hypoxic conductions caused by cord compression, reinforce oxidative stress, aggravate edema, and increase the permeability of the blood-spinal cord barrier. ${ }^{4}$ In addition, nicotine may worsen the severity of ischemia-reperfusion injury following decompression of the spinal cord, as demonstrated in models of myocardial infarction, brain injury, and necrotizing enterocolitis. ${ }^{15,21,30}$ In clinical studies, smoking has been shown to be associated with poor wound and bone healing and increased rates of pseudarthrosis and nonunion. $^{10,14}$ Decreased recovery in smokers is therefore likely due to a combination of vascular changes, impaired bone remodeling, and increased risk of complications. Future research is required to evaluate whether smoking cessation improves outcomes.

A longer duration of symptoms and impaired gait may 
indicate more severe degenerative changes, cord compression, and histological damage. Some DCM patients, however, remain neurologically stable and relatively mild for extended periods of time, whereas others deteriorate rapidly. ${ }^{26}$ The duration of symptoms is likely to have a greater impact on outcomes in patients with progression of myelopathy; in these cases, a substantial delay of surgery may prevent optimal outcomes. It is therefore necessary to diagnose myelopathy at an early stage in the disease course and to identify patients at a high risk of progression. Important predictors of neurological deterioration include the following: 1) circumferential cord compression shown on axial MRI; 22 2) an "angular-edged" spinal cord, defined as an acute angled or lateral corner at one or both sides; ${ }^{23}$ 3) greater range of preoperative neck and head motion; ${ }^{14}$ ) lower segmental lordotic angle and greater percentage of vertebral slip; ${ }^{18}$ and 5) segmental instability and reduced diameter of the CSF column. ${ }^{12}$ These patients with progressive myelopathy should be recommended surgery and counseled as to the risks of delaying intervention.

\section{Limitations}

This large prospective study represents the first analysis of important predictors of a severity-dependent MCID. This study has certain limitations: 1) the follow-up rate at 24 months was only $74.02 \%$; however, we accounted for missing data using a last-value-carry-forward imputation technique and were able to obtain mJOA scores for $92.46 \%$ of the sample; and 2) the reliability of the mJOA and other predictor variables such as duration of symptoms is unknown.

\section{Conclusions}

In this large multinational prospective cohort, $70 \%$ of patients treated surgically for DCM exhibited a meaningful functional gain on the mJOA scale. The key predictors of achieving an MCID on the MJOA scale were younger age, shorter duration of symptoms, nonsmoking status, and lack of significant gait impairment.

\section{References}

1. Barnes MP, Saunders M: The effect of cervical mobility on the natural history of cervical spondylotic myelopathy. $\mathbf{J}$ Neurol Neurosurg Psychiatry 47:17-20, 1984

2. Benzel EC, Lancon J, Kesterson L, Hadden T: Cervical laminectomy and dentate ligament section for cervical spondylotic myelopathy. J Spinal Disord 4:286-295, 1991

3. Copay AG, Glassman SD, Subach BR, Berven S, Schuler TC, Carreon LY: Minimum clinically important difference in lumbar spine surgery patients: a choice of methods using the Oswestry Disability Index, Medical Outcomes Study Questionnaire Short Form 36, and pain scales. Spine J 8:968-974, 2008

4. Fan ZK, Cao Y, Lv G, Wang YS, Guo ZP: The effect of cigarette smoke exposure on spinal cord injury in rats. J Neurotrauma 30:473-479, 2013

5. Fehlings MG, Ibrahim A, Tetreault L, Albanese V, Alvarado M, Arnold P, et al: A global perspective on the outcomes of surgical decompression in patients with cervical spondylotic myelopathy: results from the prospective multicenter AOSpine international study on 479 patients. Spine (Phila Pa 1976) 40:1322-1328, 2015
6. Fehlings MG, Tetreault L, Nater A, Choma T, Harrop J, Mroz T, et al: The aging of the global population: the changing epidemiology of disease and spinal disorders. Neurosurgery 77 (Suppl 4):S1-S5, 2015

7. Fehlings MG, Tetreault LA, Wilson JR, Skelly AC: Cervical spondylotic myelopathy: current state of the art and future directions. Spine (Phila Pa 1976) 38 (22 Suppl 1):S1-S8, 2013

8. Fehlings MG, Wilson JR, Kopjar B, Yoon ST, Arnold PM, Massicotte EM, et al: Efficacy and safety of surgical decompression in patients with cervical spondylotic myelopathy: results of the AOSpine North America prospective multicenter study. J Bone Joint Surg Am 95:1651-1658, 2013

9. Gons RA, van Norden AG, de Laat KF, van Oudheusden LJ, van Uden IW, Zwiers MP, et al: Cigarette smoking is associated with reduced microstructural integrity of cerebral white matter. Brain 134:2116-2124, 2011

10. Hilibrand AS, Fye MA, Emery SE, Palumbo MA, Bohlman $\mathrm{HH}$ : Impact of smoking on the outcome of anterior cervical arthrodesis with interbody or strut-grafting. J Bone Joint Surg Am 83-A:668-673, 2001

11. Iwahashi M, Matsuzaki H, Tokuhashi Y, Wakabayashi K, Uematsu Y: Mechanism of intervertebral disc degeneration caused by nicotine in rabbits to explicate intervertebral disc disorders caused by smoking. Spine (Phila Pa 1976) 27:1396-1401, 2002

12. Kong LD, Meng LC, Wang LF, Shen Y, Wang P, Shang ZK: Evaluation of conservative treatment and timing of surgical intervention for mild forms of cervical spondylotic myelopathy. Exp Ther Med 6:852-856, 2013

13. Kopjar B, Tetreault L, Kalsi-Ryan S, Fehlings M: Psychometric properties of the modified Japanese Orthopaedic Association scale in patients with cervical spondylotic myelopathy. Spine (Phila Pa 1976) 40:E23-E28, 2015

14. Lau D, Chou D, Ziewacz JE, Mummaneni PV: The effects of smoking on perioperative outcomes and pseudarthrosis following anterior cervical corpectomy: Clinical article. J Neurosurg Spine 21:547-558, 2014

15. Lawrence J, Xiao D, Xue Q, Rejali M, Yang S, Zhang L: Prenatal nicotine exposure increases heart susceptibility to ischemia/reperfusion injury in adult offspring. J Pharmacol Exp Ther 324:331-341, 2008

16. Nakashima H, Tetreault LA, Nagoshi N, Nouri A, Kopjar $\mathrm{B}$, Arnold PM, et al: Does age affect surgical outcomes in patients with degenerative cervical myelopathy? Results from the prospective multicenter AOSpine International study on 479 patients. J Neurol Neurosurg Psychiatry [epub ahead of print], 2015

17. Nouri A, Tetreault L, Singh A, Karadimas SK, Fehlings MG: Degenerative cervical myelopathy: epidemiology, genetics, and pathogenesis. Spine (Phila Pa 1976) 40:E675-E693, 2015

18. Oshima Y, Seichi A, Takeshita K, Chikuda H, Ono T, Baba S, et al: Natural course and prognostic factors in patients with mild cervical spondylotic myelopathy with increased signal intensity on T2-weighted magnetic resonance imaging. Spine (Phila Pa 1976) 37:1909-1913, 2012

19. Parker SL, Mendenhall SK, Shau D, Adogwa O, Cheng JS, Anderson WN, et al: Determination of minimum clinically important difference in pain, disability, and quality of life after extension of fusion for adjacent-segment disease. J Neurosurg Spine 16:61-67, 2012

20. Parker SL, Mendenhall SK, Shau DN, Adogwa O, Anderson WN, Devin CJ, et al: Minimum clinically important difference in pain, disability, and quality of life after neural decompression and fusion for same-level recurrent lumbar stenosis: understanding clinical versus statistical significance. J Neurosurg Spine 16:471-478, 2012

21. Przyklenk K: Nicotine exacerbates postischemic contractile 
dysfunction of 'stunned' myocardium in the canine model. Possible role of free radicals. Circulation 89:1272-1281, 1994

22. Shimomura T, Sumi M, Nishida K, Maeno K, Tadokoro K, Miyamoto $\mathrm{H}$, et al: Prognostic factors for deterioration of patients with cervical spondylotic myelopathy after nonsurgical treatment. Spine (Phila Pa 1976) 32:2474-2479, 2007

23. Sumi M, Miyamoto H, Suzuki T, Kaneyama S, Kanatani T, Uno K: Prospective cohort study of mild cervical spondylotic myelopathy without surgical treatment. J Neurosurg Spine 16:8-14, 2012

24. Terao S, Sobue G, Hashizume Y, Li M, Inagaki T, Mitsuma $\mathrm{T}$ : Age-related changes in human spinal ventral horn cells with special reference to the loss of small neurons in the intermediate zone: a quantitative analysis. Acta Neuropathol 92:109-114, 1996

25. Terao S, Sobue G, Hashizume Y, Shimada N, Mitsuma T: Age-related changes of the myelinated fibers in the human corticospinal tract: a quantitative analysis. Acta Neuropathol 88:137-142, 1994

26. Tetreault L, Goldstein CL, Arnold P, Harrop J, Hilibrand A, Nouri A, et al: Degenerative cervical myelopathy: a spectrum of related disorders affecting the aging spine. Neurosurgery 77 (Suppl 4):S51-S67, 2015

27. Tetreault L, Le D, Côté P, Fehlings M: The practical application of clinical prediction rules: a commentary using case examples in surgical patients with degenerative cervical myelopathy. Global Spine J 5:457-465, 2015

28. Tetreault L, Nouri A, Kopjar B, Côté P, Fehlings MG: The minimum clinically important difference of the Modified Japanese Orthopaedic Association Scale in patients with degenerative cervical myelopathy. Spine (Phila Pa 1976) 40:1653-1659, 2015
29. Tracy JA, Bartleson JD: Cervical spondylotic myelopathy. Neurologist 16:176-187, 2010

30. Wang L, Kittaka M, Sun N, Schreiber SS, Zlokovic BV: Chronic nicotine treatment enhances focal ischemic brain injury and depletes free pool of brain microvascular tissue plasminogen activator in rats. J Cereb Blood Flow Metab 17:136-146, 1997

31. Yan C, Avadhani NG, Iqbal J: The effects of smoke carcinogens on bone. Curr Osteoporos Rep 9:202-209, 2011

\section{Disclosures}

Dr. Arnold reports owning stock in Evoke Medical and Z-Plasty; he is a consultant for Medtronic Sofamor Danek, Stryker Spine, and FzioMed. The data used in this research were collected with financial support from AOSpine International and AOSpine North America.

\section{Author Contributions}

Conception and design: Fehlings. Acquisition of data: Fehlings, Kopjar, Arnold. Analysis and interpretation of data: Fehlings, Tetreault, Wilson, Kotter, Nouri, Kopjar, Arnold. Drafting the article: all authors. Critically revising the article: Fehlings, Tetreault, Wilson, Kotter, Côté, Kopjar, Arnold. Reviewed submitted version of manuscript: all authors. Approved the final version of the manuscript on behalf of all authors: Fehlings. Statistical analysis: Kopjar. Study supervision: Fehlings.

\section{Correspondence}

Michael G. Fehlings, Division of Neurosurgery, University of Toronto, Toronto Western Hospital, 399 Bathurst St., Toronto, ON M5T 2S8, Canada. email: michael.fehlings@uhn.ca. 